\title{
Effect of Tooth-whitening Procedures on Stained Nanohybrid Composites: Spectrophotometric Analysis
}

\author{
Sruthi M Sunildath ${ }^{1}$, Josey Mathew ${ }^{2}$, Liza George ${ }^{3}$, Sinju Paul ${ }^{4}$, Dhanya John ${ }^{5}$, Aleesha Joy ${ }^{6}$
}

\begin{abstract}
Aim: To evaluate and compare the staining of a nanohybrid composite resin by coffee and turmeric powder and to determine the degree of lightening that could be achieved by using contemporary self-applied at-home products and in-office whitening techniques.

Materials and methods: Thirty-six samples of standardized dimensions (10 mm diameter, $2 \mathrm{~mm}$ thick disks) were fabricated using GC solare sculpt A2 shade. The color of each specimen was measured ( $L, a, b$ values) at baseline with SpectroShade Micro. Samples were randomly allocated into three groups of coffee, turmeric solution, distilled water, and placed in $50 \mathrm{~mL}$ of each test solution. The color of each specimen was measured ( $L, a, b$ values) after 7 days to determine the color change. Each group was further divided into four subgroups according to the whitening treatment. Subgroup A-crest 3D white toothpaste (applied twice daily for 7 days), subgroup B-Polanight (45 minutes a day for 4 days), subgroup C - polaoffice (8 minutes each for three times), and subgroup D-Shofu polishing kit (applied once). After placing all specimens in distilled water for 24 hours, the color was measured again using a spectrophotometer. The effectiveness of whitening protocols was assessed by subtracting baseline color index values from those measured after whitening.

Results: Group II (turmeric solution) showed greater color change $(\Delta E)$ after staining for 1 week. There was significant difference in color changes imparted following whitening treatments with crest 3D white toothpaste after staining with coffee and turmeric solution.

Conclusion: Within the limitations of this in vitro study, it was observed that the whitening treatment with crest 3D white toothpaste is an effective method for reversing the color changes imparted by coffee and turmeric on the nanohybrid composite resin.

Clinical significance: A composite resin stained by coffee and turmeric can be lightened to a clinically perceptible level by crest 3D white toothpaste.

Keywords: Laboratory research, Nanohybrid composite, Peroxide, Sodium hexametaphosphate, Spectrophotometer, Tooth whitening.

Conservative Dentistry and Endodontic Journal (2019): 10.5005/jp-journals-10048-0052
\end{abstract}

\section{INTRODUCTION}

A beautiful smile can impact the level of self-esteem and it makes the person more confident. Teeth that are intact, properly aligned, and not discolored have a positive psychological impact. There are many factors in determining the esthetics of a smile of which tooth color is an essential component in it.

Resin-based restoratives are increasingly being used in dentistry, mainly because of their esthetic quality and good physical properties. Composites can mimic the natural color and shade of the tooth. The nanohybrid composite combines nanomeric and conventional fillers and they offer high translucency, high polish, superior gloss, and adequate mechanical properties. ${ }^{1,2}$ These superior esthetic properties of the nanohybrid composite resin enable them to be used as anterior restorations.

Exogenous colorants from food and drinks can stain composites due to adsorption. Over many years, studies have been conducted to measure these staining by beverages such as fruit juices, tea, coffee, soy sauce, and cola and food spices. ${ }^{3-5}$ Coffee and turmeric that have various medicinal benefits are commonly used by Indians. ${ }^{6}$ Both materials have the propensity to stain esthetic restorative materials.

Evaluation of staining of composites can be done by visual and instrumental techniques. ${ }^{7}$

Visual techniques can cause errors due to subjective variations in color perception. ${ }^{8}$ A spectrophotometer and a colorimeter can be used as alternatives as they are less subjected to variations. ${ }^{9}$

\begin{abstract}
${ }^{1-6}$ Department of Conservative Dentistry and Endodontics, Annoor Dental College and Hospital, Ernakulam, Kerala, India

Corresponding Author: Sruthi M Sunildath, Department of Conservative Dentistry and Endodontics, Annoor Dental College and Hospital, Ernakulam, Kerala, India, Phone: +91 9539831494, e-mail: sruthims009@gmail.com
\end{abstract}

How to cite this article: Sunildath SM, Mathew J, George L, et al. Effect of Tooth-whitening Procedures on Stained Nanohybrid Composites: Spectrophotometric Analysis. Cons Dent Endod J 2019;4(2):25-29.

Source of support: Nil

Conflict of interest: None

The purposes of this study is to measure the staining of a nanohybrid composite resin (GC solare sculpt, Japan) by coffee and turmeric powder and to determine the degree of lightening that could be gained by using contemporary self-applied at-home products and in-office whitening techniques.

\section{A IM}

The purpose of this study is to evaluate and compare

- The staining of a nanohybrid composite resin (GC solare sculpt, Japan) by coffee and turmeric powder.

- The degree of lightening that could be achieved by using contemporary self-applied at-home products (SDI Polanight and crest 3D white toothpaste) and in-office techniques (SDI polaoffice and Shofu polishing kit). 


\section{Materials and Methods}

Samples of standardized dimensions (10 $\mathrm{mm}$ diameter, $2 \mathrm{~mm}$ thick disks) were fabricated using GC solare sculpt A2 shade $(n=36)$ (Fig. 1). The color of each specimen was measured ( $L, a, b$ values) at baseline with SpectroShade Micro II (MHT Switzerland).

\section{Staining}

Samples were randomly allocated into three groups of coffee, turmeric solution, and distilled water and placed in $50 \mathrm{~mL}$ of each test solution. Coffee solution was prepared by using $10 \mathrm{~g}$ of coffee powder to $50 \mathrm{~mL}$ of hot water. Turmeric solution was prepared by adding $1.0 \mathrm{~g}$ of turmeric powder to $50 \mathrm{~mL}$ of boiling distilled water. All solutions were freshly prepared and replaced daily for 7 days. The color of each specimen was measured $(L, a, b$ values) after 7 days to determine the color change (Fig. 2).

Total $\Delta E^{*}$ color change was calculated according to the expression:

$$
\Delta E^{*}=\left[(\Delta L *)^{2}+\left(\Delta a^{*}\right)^{2}+(\Delta b *)^{2}\right]^{1 / 2}
$$

where $L^{*}$ is lightness $\left(-L^{*}=\right.$ black; $+L^{*}=$ white), $a^{*}$ is green-red $\left(-a^{*}=\right.$ green; $+a^{*}=$ red $), b^{*}$ is blue-yellow $\left(-b^{*}=\right.$ blue; $+b^{*}=$ yellow $)$.

\section{Whitening Treatment}

Each group was further divided into four subgroups according to the whitening treatment: subgroup $\mathrm{A}$-crest 3D white toothpasteProcter and Gamble Cincinnati, $\mathrm{OH}$, United States (applied twice daily for 7 days_Fig. 3); subgroup B-Polanight 22\%-SDI Polanight Australia (45 minutes a day for 4 days-Fig. 4); subgroup C-Polaoffice $35 \%$ hydrogen peroxide, Polaoffice Bleaching, SDI Limited, Bayswater, Victoria, Australia (8 minutes each for three times-Fig. 5); and subgroup D-Shofu polishing kit (polished with a polishing disk on a slow-speed handpiece for 10 seconds at moderate pressure-Fig. 3). Each of the whitening products were applied in a manner simulating at-home or in-office treatment and as per manufacturer's instructions. After 24 hours in distilled water, all specimens were measured for color change using the spectrophotometer and the effectiveness of whitening protocols was assessed by subtracting baseline color index values from those measured after whitening.

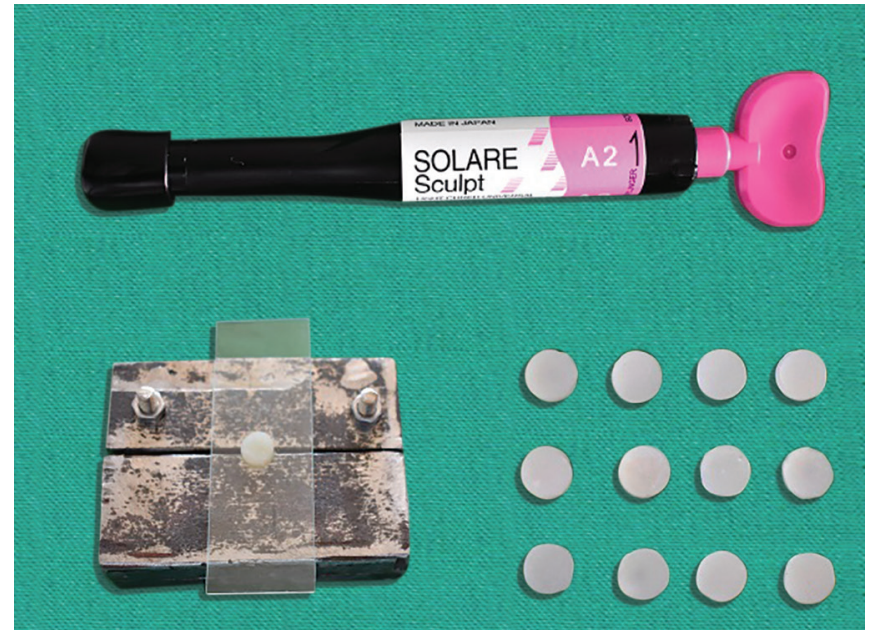

Fig. 1: Composite disk ( $2 \mathrm{~mm}$ thick, $10 \mathrm{~mm}$ diameter) preparation and samples in one group

\section{Statistical Analysis}

Data were analyzed using the SPSS version 24 software and a confidence level of $95 \%$ was set $(p<0.05)$. The one-way ANOVA was used for comparison among the groups. The Tukey HSD test was done to compare among subgroups.

\section{Results}

Spectrophotometric analysis of composite specimens after staining for 1 week showed greater $\Delta E$ value for group II, followed by group I (Table 1).

The Tukey HSD test was done to compare two staining methods and it was observed that there was statistically significant difference between control and staining groups. But there was no significant difference between group I and group II (Table 2).

The one-way ANOVA was used to compare among groups after whitening treatments and in all the groups the $p$ value was less than 0.05 . There was significant difference in color changes imparted by whitening treatments after staining by three methods (Table 3 ).

Multiple comparison between subgroups was done using the Tukey HSD test. Pairwise comparisons were significant between all subgroups except between subgroups B and D (polanight and polish) in the coffee staining group. In the turmeric group, subgroup A (crest 3D white toothpaste) showed statistically significant difference with all the other groups $(p<0.05)$ (Table 4$)$.

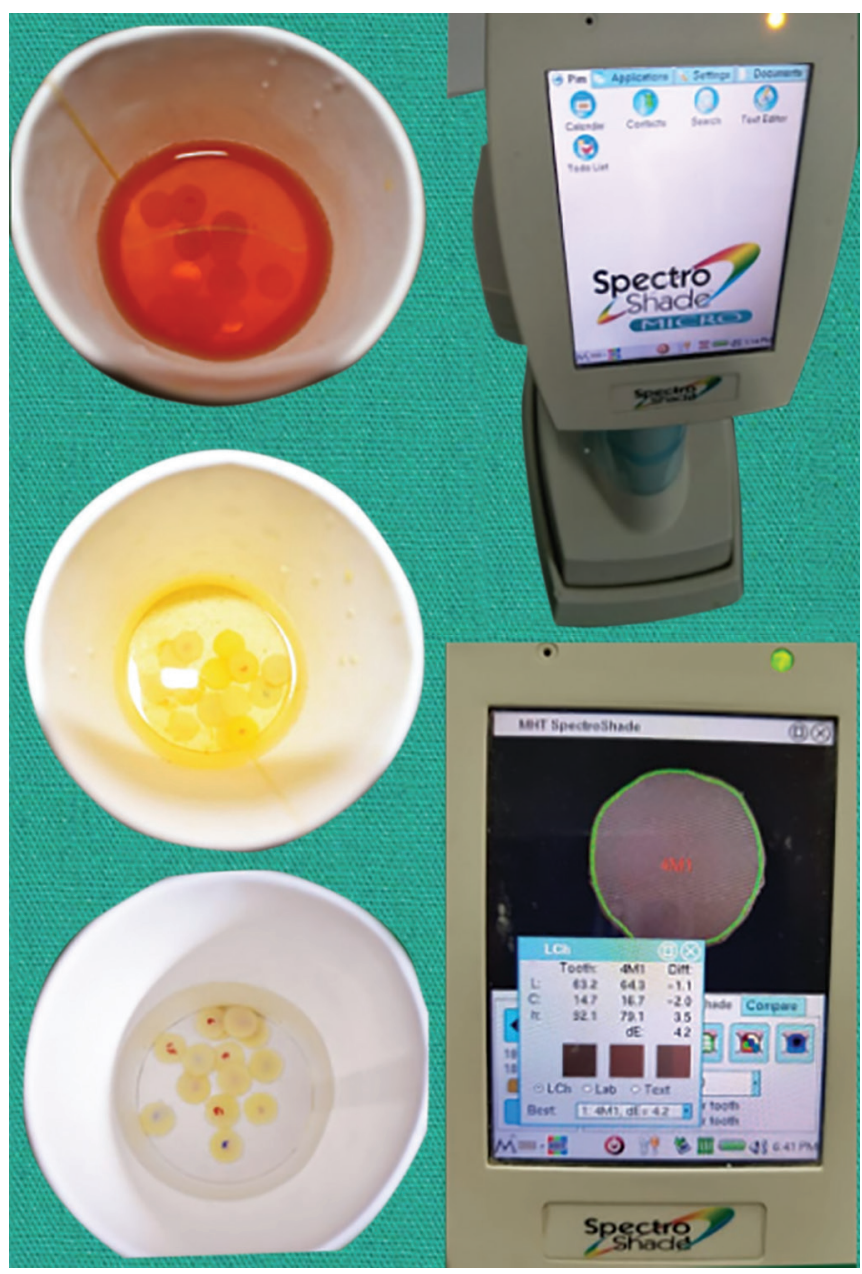

Fig. 2: Staining methods and spectrophotometer 


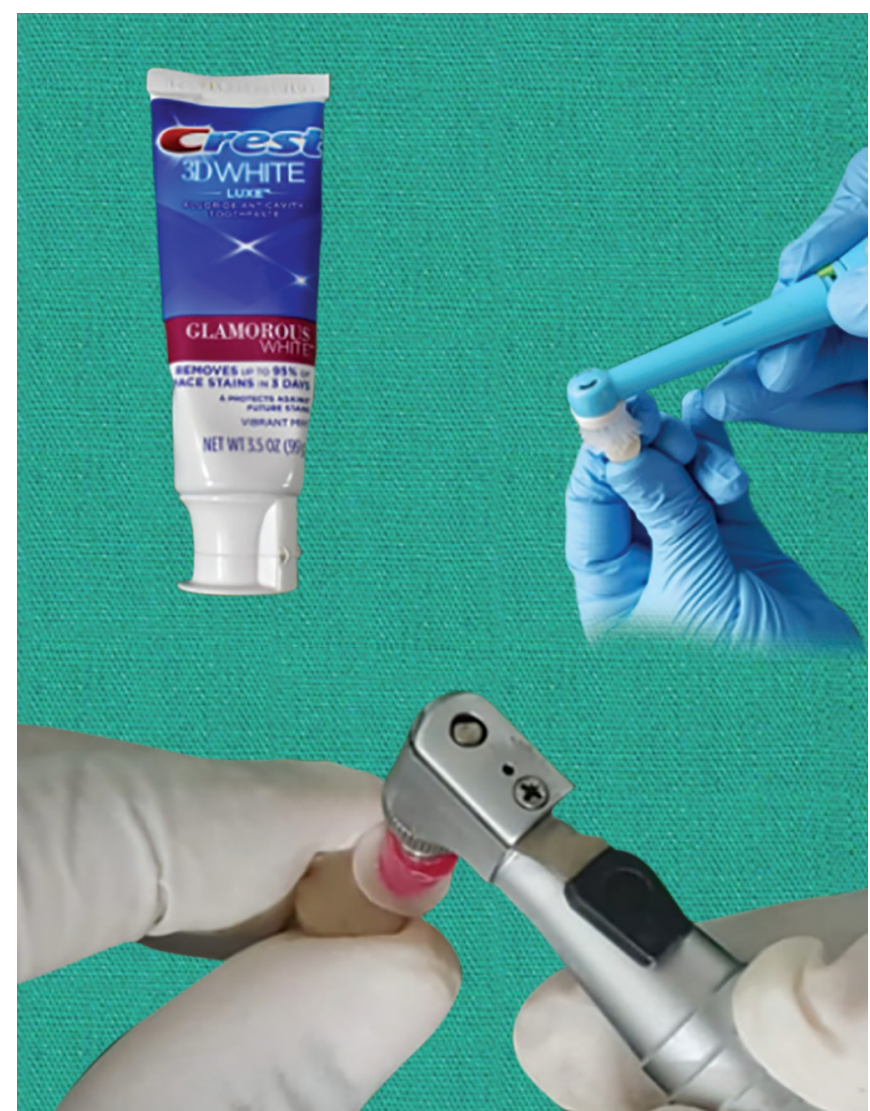

Fig. 3: Whitening treatment by crest toothpaste and polish

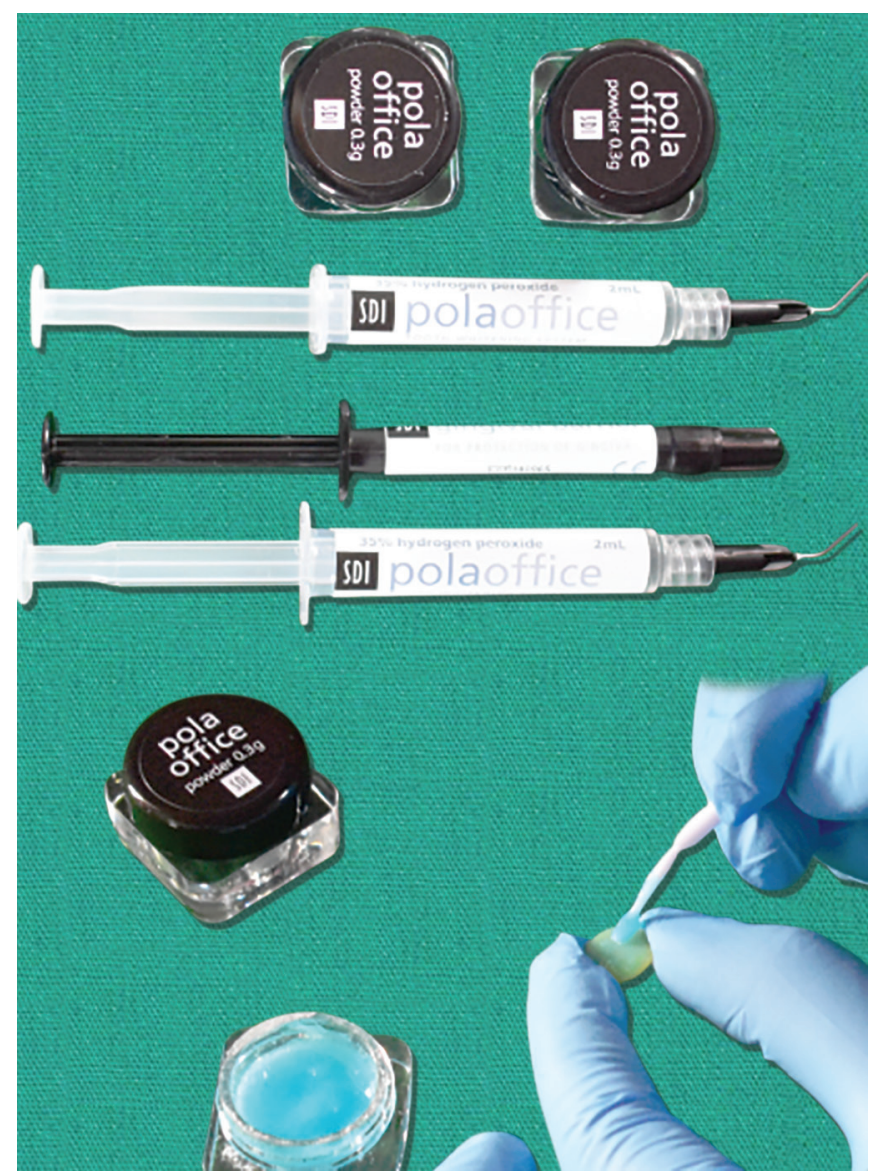

Fig. 5: Whitening treatment by Polaoffice

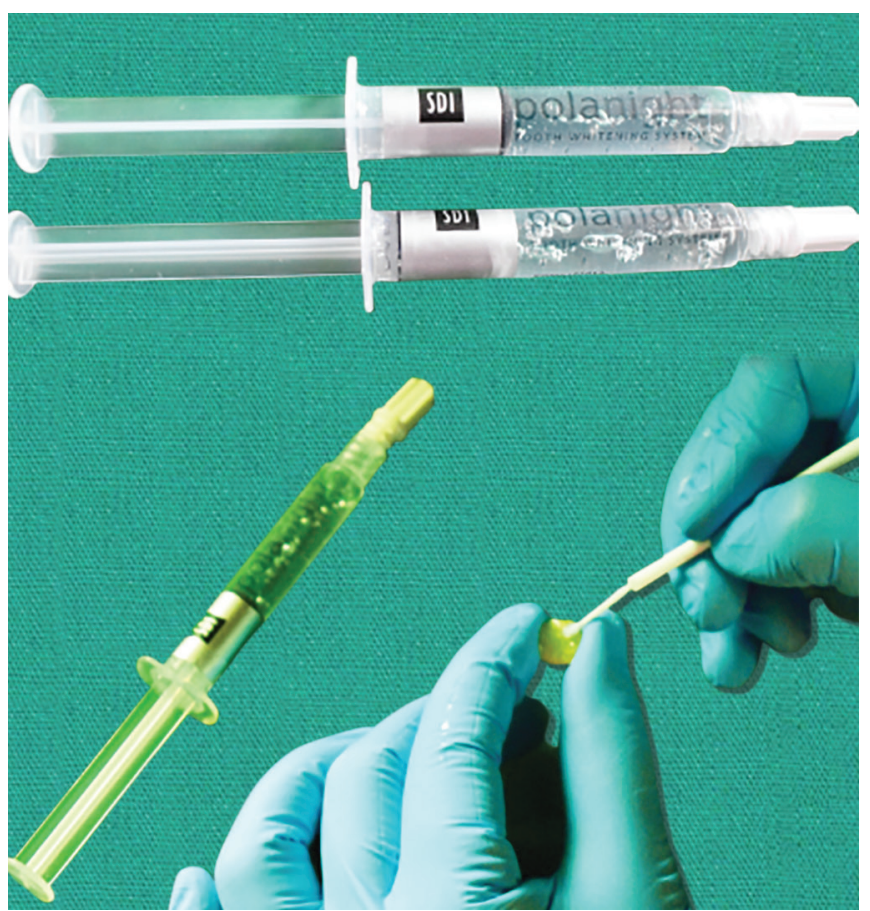

Fig. 4: Whitening treatment by Polanight

Table 1: Mean $\Delta L, \Delta a, \Delta b$, and $\Delta E$ values of composite specimens after staining for 1 week

\begin{tabular}{lllll}
\hline Groups & $\Delta L$ & $\Delta a$ & $\Delta b$ & $\Delta E$ \\
\hline Group I & -3.3 & -6.2 & 4.2 & 8.15 \\
Group II & -4.4 & -7.2 & 5.1 & 9.94 \\
Group III & -0.01 & -1.8 & 0.8 & 1.96 \\
\hline
\end{tabular}

Table 2: Comparisons between three staining solutions using Tukey HSD

\begin{tabular}{llclll}
\hline Groups & Groups & Mean difference & Sig. & F & Sig. \\
\hline I & B & 0.79733 & 0.478 & 35.279 & 0.001 \\
& C & $5.31400^{*}$ & 0.000 & & \\
II & A & -0.79733 & 0.478 & & \\
& C & $4.51667^{*}$ & 0.000 & & \\
III & A & $-5.31400^{*}$ & 0.000 & & \\
& B & $-4.51667^{*}$ & 0.000 & & \\
\hline
\end{tabular}

${ }^{*}$ The mean difference is significant at the 0.05 level

\section{Discussion}

Composites are constantly exposed to saliva, beverages, and food stains, so it is important to determine its staining susceptibility. Discoloration of composite has been reported to occur at three levels: surface (or external), subsurface, and body (or intrinsic). Subsurface stains are attributed to surface stains diffusing into superficial resin layers, with pigments attaching to potentially reactive chemicals within the composite. Intrinsic stain mostly is ascribed to physicochemical reactions occurring deep within the composite. $^{10}$

Resin matrix chemistry, filler loading, particle size, and degree of conversion are known to affect water sorption of the composite, therefore the nature and severity of composite staining are different for each manufacturer's product. ${ }^{11}$ Nanohybrid composites are those that contain milled glass fillers and discrete nanoparticles $(40-50 \mathrm{~nm})$ as the dispersed phase. They provide better mechanical strength and surface finish than hybrid composites. ${ }^{12}$ 
Table 3: Mean and standard deviation of $\Delta E$ after whitening treatment of the stained composite

\begin{tabular}{llrllll}
\hline Groups & Subgroups & $n$ & Mean & Std deviation & $F$ & Sig. \\
\hline Group I & A & 3 & 6.640 & 0.29445 & 106.320 & 0.000 \\
& B & 3 & 7.837 & 0.06351 & & \\
& C & 3 & 9.090 & 0.08660 & & \\
& D & 3 & 7.870 & 0.12124 & & \\
& Total & 12 & 7.8592 & 0.91610 & & \\
Group II & A & 3 & 5.540 & 0.0000 & 58.050 & 0.000 \\
& B & 3 & 6.827 & 0.14434 & & \\
& C & 3 & 7.060 & 0.23065 & & \\
& D & 3 & 6.697 & 0.14434 & & \\
& Total & 12 & 6.5308 & 0.62669 & & \\
Group III I & A & 3 & 1.170 & 0.00000 & 7.090 & 0.012 \\
& B & 3 & 1.387 & 0.15011 & & \\
& C & 3 & 1.360 & 0.00000 & & \\
& D & 3 & 1.140 & 0.06928 & & \\
& Total & 12 & 1.2642 & 0.13487 & & \\
\hline
\end{tabular}

Staining of resins by fluid pigments and beverages is caused by adsorption or absorption (the uptake of substances into or through tissues) of colorants by resins. ${ }^{13}$ Conjugated diarylhepnoids like curcumin are responsible for orange color and staining of turmeric solution. ${ }^{12}$ Staining by coffee is due to tannic acid and discoloration from coffee is due to both the surface adsorption and absorption of colorants. ${ }^{14}$

For standardized and reproducible evaluation of color changes of restorative materials, spectrophotometers are used for analysis of $L^{*} a^{*} b^{*}$ values according to the CIELAB system. ${ }^{15}$ It contain monochromators and photodiodes that measure the reflectance curve every $10 \mathrm{~nm}$ or less. ${ }^{16}$ The Commission Internationale del'Eclairage (CIELAB) color coordinates system provides information about location of object color in a uniform three-dimensional color space. It quantifies the color in terms of three coordinate values, $L^{*}, a^{*}$, and $b^{*}$. Here $L^{*}$ represents brightness or lightness (value) and $a^{*}$ and $b^{*}$ serve as numeric correlates both for hue and chroma. ${ }^{17}$ The $a^{*}$ and $b^{*}$ values represent position on a red/green and yellow/blue axis, respectively: $+a^{*}=\mathrm{red}$, $-a^{*}=$ green, $+b^{*}=$ yellow, and $-b^{*}=$ blue. Values of $\Delta E$ between 0 and 2 are imperceptible, those between 2 and 3 are just perceptible, values from 3 to 8 are moderately perceptible, and values above 8 are markedly perceptible. ${ }^{18}$

A $\Delta E$ value of 3.7 or less is considered to be clinically acceptable. ${ }^{19,20}$ Stober et al. concluded that turmeric solution and red wine caused the most severe discoloration $(\Delta E>10)$ than tea, coffee, and mouth rinse over 4 and 8 weeks. ${ }^{21}$ The study by Karadas showed clinically perceptible color change in composite when immersed in black tea or coffee. ${ }^{22}$ In the present study, color change in the dental resin material was observed with turmeric and coffee $(\Delta E>8)$; greater staining was observed with turmeric $(\Delta E=9.94)$. But there is no statistically significant difference between groups.

Polaoffice contains $35 \%$ hydrogen peroxide, and Polanight contains $22 \%$ carbamide peroxide. When activated by heat, light, or $\mathrm{pH}$, hydrogen peroxide $\left(\mathrm{H}_{2} \mathrm{O}_{2}\right)$ dissociates via cleavage of $\mathrm{O}-\mathrm{H}$ and $\mathrm{O}-\mathrm{O}$ bonds to produce $\mathrm{H}^{*},{ }^{*} \mathrm{OOH}$, and $2{ }^{*} \mathrm{OH}$ radicals that are capable of decomposing conjugated double bonds and ring structures present within stain. ${ }^{23}$ Hydrogen peroxide and urea are the breakdown products of carbamide peroxide, and urea further dissociates into carbon dioxide and ammonia. This creates an alkaline environment capable of producing the perhydroxyl anion $\left(\mathrm{HO}_{2}{ }^{-}\right)$, a compound shown to further the whitening effect. ${ }^{24}$ In this study, Polaoffice showed significant whitening compared to other whitening treatments in coffee group.

The crest 3D white toothpaste showed significant difference with all other whitening treatments in both coffee and turmeric groups. Peroxide-based systems were not able to whiten the composite as the whitening toothpaste. The crest 3D white toothpaste contains sodium hexametaphosphate that has multiple binding sites translates to greater coverage of the tooth surface, increasing its potential retention and substantivity. ${ }^{25,26}$ Numerous clinical and in vitro studies have demonstrated sodium hexametaphosphate's stain-control benefits in dentifrice and chewing gum delivery systems. ${ }^{27-31}$ Study by Manis et al. showed that whitening toothpaste influenced the color stability of the composite resin. ${ }^{32}$ Abrasive action during brushing and presence of sodium hexametaphosphate might have contributed to the better results by the crest 3D white toothpaste.

Table 4: Multiple comparison among subgroups using the Tukey HSD test

\begin{tabular}{|c|c|c|c|c|c|c|c|}
\hline \multicolumn{4}{|c|}{ Group I } & \multicolumn{4}{|c|}{ Group II } \\
\hline Subgroups (I) & Subgroups (J) & Mean difference $(I-J)$ & Sig. & Subgroups (I) & Subgroups (J) & Mean difference $(I-J)$ & Sig. \\
\hline \multirow[t]{3}{*}{ A } & 3 & $-2.45000^{*}$ & 0.000 & A & 3 & $-1.52000^{*}$ & 0.000 \\
\hline & 2 & $-1.19667^{*}$ & 0.000 & & 2 & $-1.28667^{*}$ & 0.000 \\
\hline & 4 & $-1.23000^{*}$ & 0.000 & & 4 & $-1.15667^{*}$ & 0.000 \\
\hline \multirow[t]{3}{*}{ B } & 1 & $1.19667^{*}$ & 0.000 & B & 1 & $1.28667^{*}$ & 0.000 \\
\hline & 3 & $-1.25333^{*}$ & 0.000 & & 3 & -0.23333 & 0.317 \\
\hline & 4 & -0.03333 & 0.995 & & 4 & 0.13000 & 0.736 \\
\hline \multirow[t]{3}{*}{ C } & 1 & $2.45000^{*}$ & 0.000 & $\mathrm{C}$ & 1 & $1.52000^{*}$ & 0.000 \\
\hline & 2 & $1.25333^{*}$ & 0.000 & & 2 & 0.233333 & 0.317 \\
\hline & 4 & $1.22000^{*}$ & 0.000 & & 4 & 0.363333 & 0.078 \\
\hline \multirow[t]{3}{*}{ D } & 1 & $1.23000^{*}$ & 0.000 & $\mathrm{D}$ & 1 & $1.15667^{*}$ & 0.000 \\
\hline & 3 & $-1.22000^{*}$ & 0.000 & & 3 & -0.36333 & 0.078 \\
\hline & 2 & 0.03333 & 0.995 & & 2 & -0.13000 & 0.736 \\
\hline
\end{tabular}

*The mean difference is significant at the 0.05 level 


\section{Conclusion}

Within the limitations of this in vitro study, it was observed that the whitening treatment with the crest 3D white toothpaste is an effective method for reversing the color changes imparted by coffee and turmeric on the nanohybrid composite resin.

\section{References}

1. Swift JrE. Nanocomposites. J Esthet Restor Dent 2005;17(1):3-4. DOI: 10.1111/j.1708-8240.2005.tb00075.x.

2. Angerame $D$, De Biasi M. Do nanofilled/nanohybrid composites allow for better clinical performance of direct restorations than traditional microhybrid composites? A systematic review. Oper Dent 2018;43(4):191-209. DOI: 10.2341/17-212-L.

3. Duc O, Betrisey E, Di Bella E, et al. Staining susceptibility of recently developed resin composite materials. J Clin Adv Dent 2018;2: 001-007.

4. Telang A, Narayana IH, Madu KS, et al. Effect of staining and bleaching on color stability and surface roughness of three resin composites: an in vitro study. Contemp Clin Dent 2018;9(3):452-456.

5. Usha C, Rao SR, George GM. A comparative evaluation of the staining capacity of microhybrid and nanohybrid resin based composite to Indian spices and food colorants: an in vitro study. Indian J Dent Res 2018;29(2):201-205. DOI: 10.4103/ijdr.IJDR_764_16.

6. Hay E, Lucariello A, Contieri M, et al. Therapeutic effects of turmeric in several diseases: an overview. Chem Biol Interact 2019;310:108729. DOI: 10.1016/j.cbi.2019.108729.

7. Spina DRF, Grossi JRA, Cunali RS, et al. Evaluation of discoloration removal by polishing resin composites submitted to staining in different drink solutions. Int Sch Res Notices 2015. 1-5. DOI: 10.1155/2015/853975

8. Moodley DS, Patel N, Moodley T, et al. Comparison of colour differences in visual versus spectrophotometric shade matching. $S$ Afr Dent J 2015;70(9):402-407.

9. Kielbassa AM, Beheim Schwarzbach NJ, Neumann K, et al. In vitro comparison of visual and computer aided pre and post tooth shade determination using various home bleaching procedures. J Prosthet Dent 2009;101(2):40-45. DOI: 10.1016/S0022-3913(09)60001-9.

10. Villalta $\mathrm{P}, \mathrm{Lu} \mathrm{H}, \mathrm{Okte} \mathrm{Z}$, et al. Effects of staining and bleaching on color change of dental composite resins. J Prosthet Dent 2006;95(2): 137-142. DOI: 10.1016/j.prosdent.2005.11.019.

11. Reinhardt J, Balbierz M, Schultz C, et al. Effect of tooth-whitening procedures on stained composite resins. Oper Dent 2019;44(1):65-75. DOI: 10.2341/17-301-L.

12. Mitra SB, Wu D, Holmes BN. An application of nanotechnology in advanced dental materials. J Am Dent Assoc 20030ct;134(10): 1382-1390. DOI: 10.14219/jada.archive.2003.0054.

13. Um CM, Ruyter IE. Staining of resin based veneering materials with coffee and tea. Quintessence Int 1991;22(5):377-386.

14. Hersek N, Canay S, Uzun G, et al. Color stability of denture base acrylic resins in three food colorants. J Prosthet Dent 1999;81(4):375-379. DOI: 10.1016/S0022-3913(99)80001-8.
15. Johnston WM. Color measurement in dentistry. J Dent 2009;37(Suppl 1):e2-e6. DOI: 10.1016/j.jdent.2009.03.011.

16. Brewer JD, Wee A, Seghi R. Advances in color matching. Dent Clin North Am 2004;48(2):341-358. DOI: 10.1016/j.cden.2004.01.004.

17. Asmussen E. An accelerated test for color stability of dental composite resins. Acta Odontol Scand 1981;39(6):329-332. DOI: 10.3109/00016358109162704.

18. Guler AU, Kurt S, Kulunk T. Effects of various finishing procedures on the staining of provisional restorative materials. J Prosthet Dent 2005;93(5):453-458. DOI: 10.1016/j.prosdent.2005.02.001.

19. Okubo SR, Kanawati A, Richards MW, et al. Evaluation of visual and instrument shade matching. J Prosthet Dent 1998;80(2):642-648. DOI: 10.1016/S0022-3913(98)70049-6.

20. Johnston WM, Kao EC. Assessment of appearance match by visual observation and clinical colorimetry. J Dent Res 1989;68(5):819-822. DOI: $10.1177 / 00220345890680051301$.

21. Stober T, Gilde H, Lenz P. Color stability of highly filled composite resin materials for facings. Dent Mater 2001;17(1):87-94. DOI: 10.1016/ S0109-5641(00)00065-8.

22. Karadas M. The effect of different beverages on the color and translucency of flowable composites. Scanning 2016;38(6):701-709. DOI: $10.1002 /$ sca.21318.

23. Epple M, Meyer F, Enax J. A critical review of modern concepts for teeth whitening. Dent J 2019;7(3):79. DOI: 10.3390/dj7030079.

24. Peixoto AC, Vaez SC, Pereira NAR, et al. High-concentration carbamide peroxide can reduce the sensitivity caused by in-office tooth bleaching: a single-blinded randomized controlled trial. J Appl Oral Sci 2018;26:e20170573. DOI: 10.1590/1678-7757-2017-0573.

25. Baig A, Kozak K, Cox ER, et al. Laboratory studies on the chemical whitening effects of a sodium hexametaphosphate dentifrice. J Clin Dent 2002;13(1):19-24.

26. Baig A, He T, Buisson J, et al. Extrinsic whitening effects of sodium hexametaphosphate-a review including a dentifrice with stabilized stannous fluoride. Compend Contin Educ Dent 2005;26(9 Suppl 1):47-53.

27. Gerlach RW, Ramsey LL, White DJ. Extrinsic stain removal with a sodium hexametaphosphate containing dentifrice comparisons to marketed controls. J Clin Dent 2002;13(1):10-14.

28. Mason S, Young S, Qaqish J, et al. Stain control with two modified stannous fluoride/sodium tripolyphosphate toothpastes: a randomised controlled proof of concept study. J Dent 2019;2:100009. DOI: 10.1016/j.jjodo.2019.100009.

29. Palmer PC, Baig AA, Suszcynsky-Meister EM, et al. In vitro evaluation of extrinsic stain prevention capability of a hexametaphosphate chewing gum. J Dent Res 2003;82(spec iss):1695.

30. Biesbrock AR, Walters $P$, Bartizek RD. A chewing gum containing $7.5 \%$ sodium hexametaphosphate inhibits stain deposition relative to a placebo chewing gum. Compend Contin Educ Dent 2004;25(4):253-264.

31. Bartizek RD, Walters $P$, Biesbrock AR. The prevention of induced stain using two levels of sodium hexametaphosphate in chewing gum. J Clin Dent 2003;14(4):77-81.

32. Manis RB, da Silva TM, Franco TT, et al. Influence of whitening toothpaste on color, roughness, and microhardness of composite resins. Eur J Gen Dent 2017;6(2):92-98. 